\title{
An inner cell wall protein (cwp1) from conidia of the entomopathogenic fungus Beauveria bassiana
}

\author{
Michael J. Bidochka, Raymond J. St Leger, Lokesh Joshi \\ and Donald W. Roberts
}

Author for correspondence: Michael J. Bidochka. Tel: +1607254 1355. Fax: +16072541242.

Boyce Thompson Institute for Plant Research, Tower Road, Cornell University, Ithaca, New York 14853, USA

\begin{abstract}
Following the removal of the rodlet layer from aerial or submerged conidia of the entomopathogenic deuteromycetous fungus Beauveria bassiana, SDSinsoluble, formic-acid-extractable proteins were found in the residual cell wall material. Two major proteins $(12.8$ and $14.0 \mathrm{kDa})$ were extracted with formic acid from fractured aerial and submerged conidia but not from blastospores. Oxidation of the sample extracted by formic acid resulted in a single protein band (15.4 kDa) as judged by SDS-PAGE. Antibodies against this cell wall protein (cwp1) did not cross-react with cell wall extracts from the entomopathogenic deuteromycetous fungi Verticillium lecanii or Metarhizium anisopliae. Western blot analysis of two-dimensional gels revealed at least three acidic isoforms (pl 4-0-4.8) of cwp1. Immunohistological studies revealed that the cwp1 was primarily localized in the cell wall of aerial and submerged conidia but not in blastospores. Immunolocalization was possible only if the conidia were previously boiled in $5 \%$ (v/v) $\beta$-mercaptoethanol. The $N$-terminal sequence of cwp1 showed no similarities with other published sequences. Our results suggest that at least two major species of SDS-insoluble, formic-acidextractable proteins exist in cell walls of $B$. bassiana aerial or submerged conidia; one is the hydrophobin which occurs in the outermost rodlet layer and the other, cwp1, occurs primarily next to the rodlet layer.
\end{abstract}

Keywords: Beauveria bassiana, entomopathogenic fungus, conidia, cell wall protein

\section{INTRODUCTION}

Beauveria bassiana is an entomopathogenic fungus that is being considered as a commercial biocontrol agent. Several methods are available for propagation of $B$. bassiana. Aerial growth of hyphae on solid or semi-solid media results in the production of conidia, while submerged growth in nutrient-rich media results in the production of blastospores (Bidochka et al., 1987). However, growth in certain types of liquid media, such as TKI medium (Thomas et al., 1987), results in the production of 'submerged conidia'. Aerial and submerged conidia are similar with respect to their stability under storage, cell wall carbohydrates, hydrophobicity, virulence toward insects, and SDS-soluble proteins (Hegedus et al., 1990, 1992). Aerial and submerged conidia also contain a rodlet layer. The major rodlet protein is SDS-insoluble and formic-acid-extractable and has been identified as a hydrophobin (Bidochka et al., 1995). Hydrophobin was not found in blastospores.
Hydrophobins polymerize on the surface of conidia and this results in a water-impermeable, hydrophobic layer (de Vries et al., 1993). This layer is, in part, responsible for protecting the conidium from desiccation (Cole et al., 1979; Wessels, 1992). Conidial hydrophobicity also contributes to conidial dispersal (Bell-Peterson et al., 1992; Lauter et al., 1992) and, in the case of certain entomopathogenic fungi, to conidial attachment to the hydrophobic insect cuticle (Boucias et al., 1988).

The ability of an entomopathogenic fungal conidium to resist desiccation, remain stable under long-term storage and to adhere to insect cuticle is an important consideration in its propagation as a biocontrol agent. We have previously identified a hydrophobin in the rodlet layer of B. bassiana conidia (Bidochka et al., 1995). Here we investigate the presence of other SDS-insoluble, formicacid-extractable proteins in cell walls of aerial and submerged conidia and blastospores of B. bassiana. 


\section{METHODS}

Organisms and growth. The fungal isolates [Beauveria bassiana RS252, Metarbizium anisopliae 2575 (formerly ME1) and Verticillium lecanii 313] were obtained from the USDA entomopathogenic fungal culture collection in Ithaca, New York, USA, and maintained on Sabouraud dextrose agar at $25^{\circ} \mathrm{C}$ to produce aerial conidia. Ten-day-old cultures containing aerial conidia were harvested in $0.02 \%$ Triton $\mathrm{X}-100$, filtered through four layers of cheesecloth, and washed four times with water.

To obtain submerged conidia $B$. bassiana was grown in a modification of TKI medium (Thomas et al., 1987) which consisted of (per litre distilled water): $50 \mathrm{~g}$ glucose, $10 \mathrm{~g} \mathrm{KNO}_{3}$, $5 \mathrm{~g} \mathrm{KH}_{2} \mathrm{PO}_{4}, 2 \mathrm{~g} \mathrm{MgSO}_{4}, 50 \mathrm{mg} \mathrm{CaCl} .2 \mathrm{H}_{2} \mathrm{O}, 50 \mathrm{mg}$ yeast extract. Cultures were grown for $5 \mathrm{~d}$ at $25^{\circ} \mathrm{C}$ and 180 r.p.m. Submerged conidia were obtained by filtering the culture through four layers of cheesecloth. The conidia were centrifuged at $3000 \mathrm{~g}$ and washed four times with water. To obtain blastospores, $B$. bassiana was propagated in $2 \%(\mathrm{w} / \mathrm{v})$ peptone, $1 \%$ (w/v) glucose for $4 \mathrm{~d}$ at $25^{\circ} \mathrm{C}$ and 180 r.p.m. (Bidochka et al., 1987). The culture was filtered, and the blastospores washed four times with water.

B. bassiana was also grown in Reddy-Wyatt insect culture medium, which is a nutrient-rich medium analogous to insect haemolymph (Reddy \& Wyatt, 1967), and in $1 \%(\mathrm{w} / \mathrm{v})$ chitin medium.

Proteins were extracted from broth cultures by adding an equal volume of $0.1 \mathrm{M}$ ammonium acetate in methanol to culture filtrates and left overnight at $-20^{\circ} \mathrm{C}$. The precipitate was removed by centrifugation at $3000 \mathrm{~g}$, washed with methanol and lyophilized.

Fracturing of conidial and blastospore cell walls. Rodlets were removed from $B$. bassiana by sonication as described by Boucias et al. (1988) except that the sonication time was extended another $5 \mathrm{~min}$. The residual material was then centrifuged at $27000 \mathrm{~g}$, washed with distilled water and lyophilized. Lyophilized conidia or blastospores $(500 \mathrm{mg}$ ) and acid-washed sand $(500 \mathrm{mg} ; 212-500 \mu \mathrm{m}$ particle diameter) were then vortexed together with liquid nitrogen in a screwtop centrifuge tube (the cap was pierced to allow for expanding nitrogen) for three periods of $15 \mathrm{~min}$ each. The fractured fungal material and sand were then suspended in $20 \mathrm{ml} 0.1 \mathrm{M}$ Tris $/ \mathrm{HCl}(\mathrm{pH} \mathrm{8.0)}$. The sand was allowed to settle for $1 \mathrm{~min}$ and the supernatant containing the fractured cell walls was removed, centrifuged at $27000 \mathrm{~g}$ and washed twice each with Tris buffer and distilled water.

Dissolution of SDSinsoluble protein with formic acid. The fractured cell walls (post $27000 \mathrm{~g}$ centrifugation) were boiled in $100 \mathrm{mM}$ Tris $/ \mathrm{HCl}(\mathrm{pH} \mathrm{6.8)}, 4 \%$ (w/v) SDS, $10 \%$ (w/v) glycerol and $0.1 \%$ bromophenol blue for $10 \mathrm{~min}$ then washed six times (until the blue dye disappeared) with distilled deionized water and lyophilized. SDS-insoluble protein from the remaining cell wall material was extracted with trifluoroacetic acid or formic acid followed by oxidation with performic acid according to the method of Wessels et al. (1991).

PAGE and protein sequencing. Electrophoresis was done either in a $12 \%(\mathrm{w} / \mathrm{v})$ polyacrylamide gel according to Laemmli (1970) or on a 4-20\% gradient gel (Bio-Rad) and gels were silver-stained or stained with Coomassie blue. Bands of interest were excised from Coomassie-blue-stained gels, electroeluted according to manufacturer's guidelines (Bio-Rad), oxidized with performic acid, separated by SDS-PAGE and silverstained.

For N-terminal protein sequencing, electrophoresis was done with the neutral buffer system described by Moos et al. (1988).
Gels were polymerized overnight and prerun at $10 \mathrm{~mA}$ per gel for $30 \mathrm{~min}$. Electroblotting was done on PVDF membrane (Immobilin-PsQ, Millipore) by tank transfer (Bio-Rad) at $100 \mathrm{~V}$ for $1 \mathrm{~h}$. The membrane was stained in a fresh solution of Coomassie blue, destained for $2 \mathrm{~h}$ and bands of interest excised. The $\mathrm{N}$-terminal sequence was determined by automated Edman degradation using an Applied Biosystems 47A gas-phase protein sequencer. Amino acid analysis was performed using the Waters (Waters Chromatography) Pico-Tag system (Henrikson \& Meredith, 1984).

Two-dimensional gel electrophoresis was done according to manufacturer's guidelines (Bio-Rad).

Preparation of antibodies and immunoblotting. The SDSinsoluble, formic-acid-extractable proteins (with or without oxidation with performic acid) from fractured conidia cell walls were separated by SDS-PAGE. The major conidial wall protein from the performic-acid-treated sample was excised from SDS gels and homogenized in $250 \mu$ distilled water. We called this protein cwp1. The suspension was sub-divided into three aliquots, mixed with Freund's complete adjuvant and injected $14 \mathrm{~d}$ apart into New Zealand White/Flemish-cross rabbits. Blood was taken after the final injection and the serum separated by centrifugation at $3000 \mathrm{~g}\left(4^{\circ} \mathrm{C}\right)$.

For Western blot analysis, proteins were electrophoretically transferred from gels onto nitrocellulose. Blots were probed with anti-cwp1 (1:200 dilution) then visualized with goat antirabbit IgG-alkaline phosphatase conjugate (Sigma). Western blot analysis was done according to the ProtoBlot Western blot alkaline phosphatase system technical manual (Promega) except that $1 \%(\mathrm{w} / \mathrm{v})$ skimmed milk powder was used as a blocking agent.

Immunofluorescence microscopy. An indirect immunofluorescence technique was performed to localize the cwp1 antigens using primary and Cy3-labelled secondary antibodies. The secondary-antibody-Cy3 conjugate was affinity pure, goat anti-rabbit IgG (Sigma).

Conidia and blastospores were boiled in $5 \%(\mathrm{v} / \mathrm{v}) \beta$-mercaptoethanol for $5 \mathrm{~min}$. The material was centrifuged and washed with PBS (137 mM NaCl, $2.7 \mathrm{mM} \mathrm{KCl}, 4.3 \mathrm{mM}$ $\left.\mathrm{Na}_{2} \mathrm{HPO}_{4} .7 \mathrm{H}_{2} \mathrm{O}, 1 \cdot 4 \mathrm{mM} \mathrm{KH}_{2} \mathrm{PO}_{4}\right), \mathrm{pH} 6.8$. The material was resuspended in a $1: 10$ dilution of primary antibody $(10 \mu \mathrm{l}$ serum in $90 \mu \mathrm{lPBS})$. The suspension was incubated at $4{ }^{\circ} \mathrm{C}$ for $2 \mathrm{~h}$ with gentle agitation, washed three times with $\mathrm{PBS}$ at $4{ }^{\circ} \mathrm{C}$, resuspended in a 1:10 dilution of secondary-antibody-Cy3 conjugate and incubated for $2 \mathrm{~h}$ at $4{ }^{\circ} \mathrm{C}$ with gentle agitation. After washing in PBS, a drop of the suspension was placed on a glass slide, examined immediately with a microscope and photographed with 1600 ASA film using a rhodamine filter. Control tests were performed with the omission of primary antibody.

Insect infection. B. bassiana (approximately $10^{6}$ conidia) was injected into the haemocoel of silkworm larvae, Bombyx mori, with a Hamilton repeating-volume syringe. Larvae died within $5 \mathrm{~d}$ and haemolymph was extracted $24 \mathrm{~h}$ and $48 \mathrm{~h}$ post-mortem, precipitated with an equal volume of $0.1 \mathrm{M}$ ammonium acetate in methanol, washed with methanol and lyophilized.

\section{RESULTS}

\section{SDS-insoluble, formic-acid-extractable conidial wall proteins}

After removal of the rodlet layer by sonication, the conidia were fractured by vortexing with sand under liquid nitrogen. The SDS-insoluble wall proteins were 


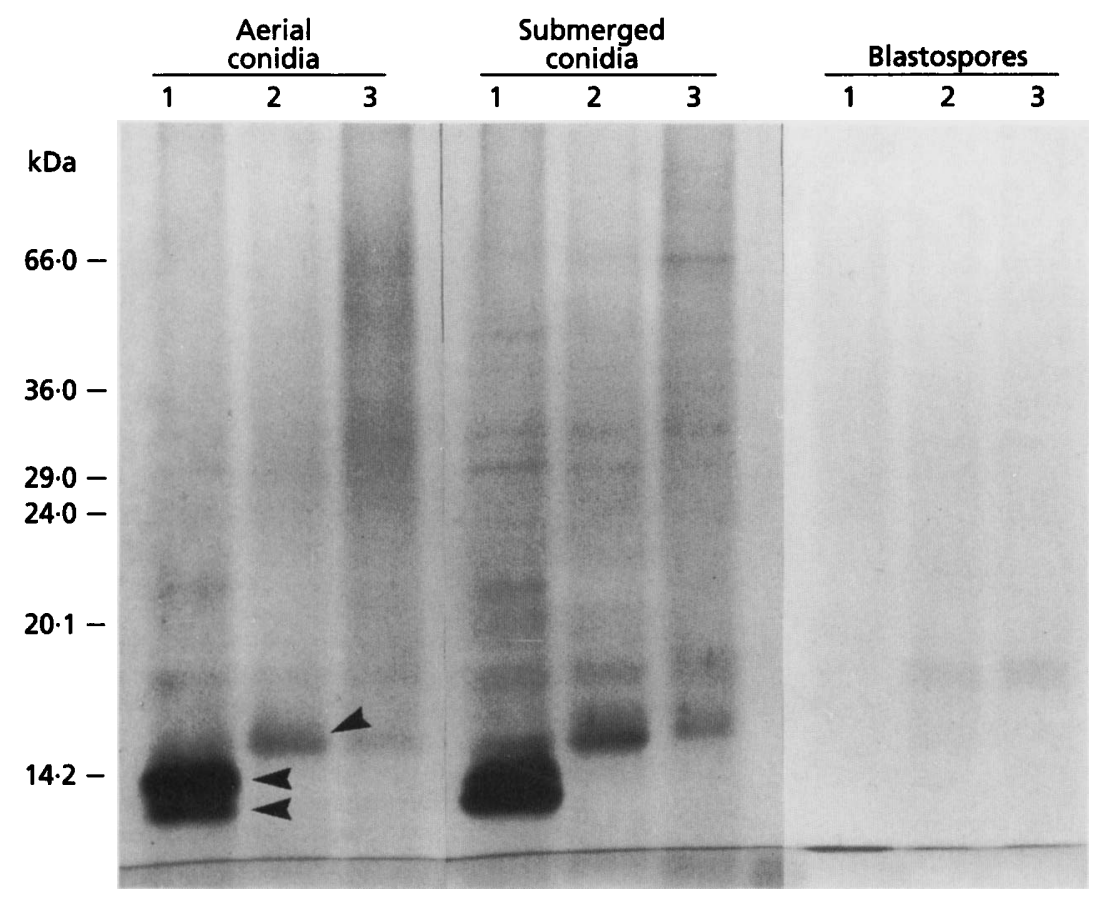

Fig. 1. SDS-insoluble proteins from fractured walls of aerial conidia, submerged conidia and blastospores of $B$. bassiana. Lanes: 1 , formic acid extracts; 2, performic acid oxidation of the formic acid extracts; 3 , performic acid extracts of the material remaining after formic acid extraction. Arrows indicate the two major proteins in the formic acid extract (lane 1: 12.8 and $14.0 \mathrm{kDa})$ and the major protein after performic acid oxidation (lane 2: $15.4 \mathrm{kDa}$ ). Proteins were subjected to $12.5 \%$ polyacrylamide gel electrophoresis followed by silver-staining. Molecular mass markers (kDa) are shown to the left of the gel.

extracted with formic acid from aerial conidia, submerged conidia and blastospores.

Two major protein bands $(12.8 \mathrm{kDa}$ and $14.0 \mathrm{kDa})$ were observed in the formic acid extracts of fractured aerial and submerged conidia but not in blastospores (Fig. 1, lane 1). Oxidation of the formic acid extracts with performic acid resulted in a single major protein of larger molecular mass $(15.4 \mathrm{kDa}$; Fig. 1, lane 2) termed cwp1. Performic acid treatment of the residual fungal cell wall material after formic acid treatment (Fig. 1, lane 3) showed results similar to oxidation of the formic acid extract. Trifluoroacetic acid extracts of the wall proteins also resulted in a single $15.4 \mathrm{kDa}$ protein (data not shown). The $12.8 \mathrm{kDa}$ and $14.0 \mathrm{kDa}$ bands were excised separately from gels and oxidized with performic acid. Both of the oxidized proteins ran as a single band of $15.4 \mathrm{kDa}$ on SDS-PAGE (data not shown).

\section{Immunological detection of cwp1}

Antiserum to cwp1 from aerial conidia showed immunoreactivity to aerial and submerged conidia wall proteins extracted with formic acid and oxidized with performic acid (Fig. 2, lane 2). However, without the performic acid treatment, formic acid wall extracts did not cross-react with cwp1 antibodies (Fig. 2, lane 1). cwp1 was not detected in blastospore extracts.

Western blot analysis of precipitated proteins (with or without oxidation with performic acid) from $B$. bassiana culture filtrates of Reddy-Wyatt insect culture medium, $1 \%(\mathrm{w} / \mathrm{v})$ chitin medium, $2 \%$ peptone- $1 \%(\mathrm{w} / \mathrm{v})$ glucose or haemolymph from infected silkworm larvae did not detect the presence of cwp1 at the $15.4 \mathrm{kDa}$ position. However, the cwp1 antibody did cross-react with a 28 and

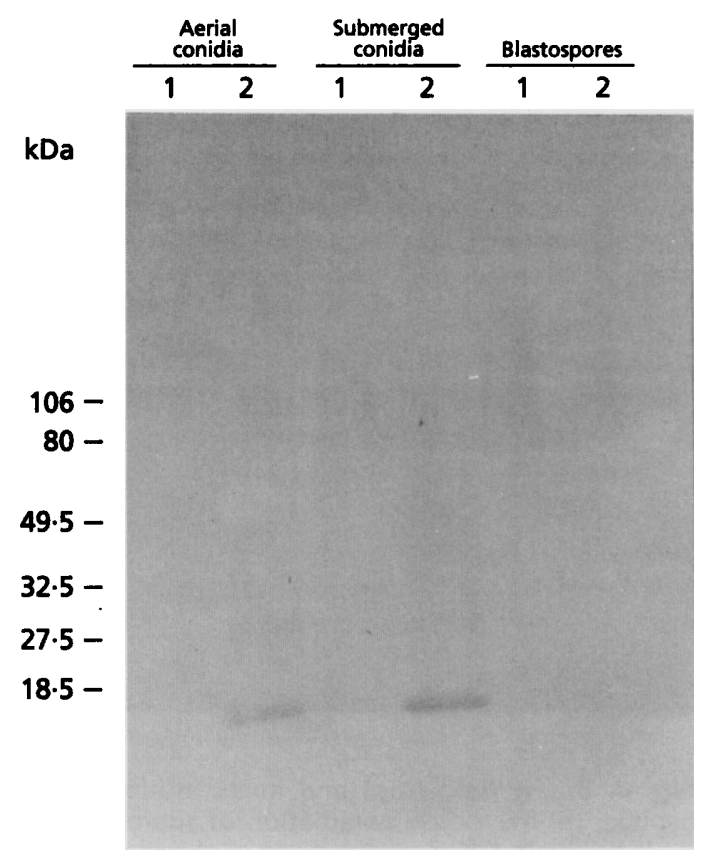

Fig. 2. Immunoblot from a 4-20\% polyacrylamide gradient gel using antiserum against cwp1 of SDS-insoluble proteins from fractured walls of aerial conidia, submerged conidia and blastospores of B. bassiana. Lanes: 1, formic acid extracts; 2 , performic acid oxidation of formic acid extracts. Molecular mass markers ( $\mathrm{kDa}$ ) are shown to the left of the gel.

$32 \mathrm{kDa}$ doublet from $B$. bassiana culture filtrates in Reddy-Wyatt medium and $2 \%$ peptone, $1 \%$ glucose medium in both the oxidized and unoxidized samples (data not shown). 

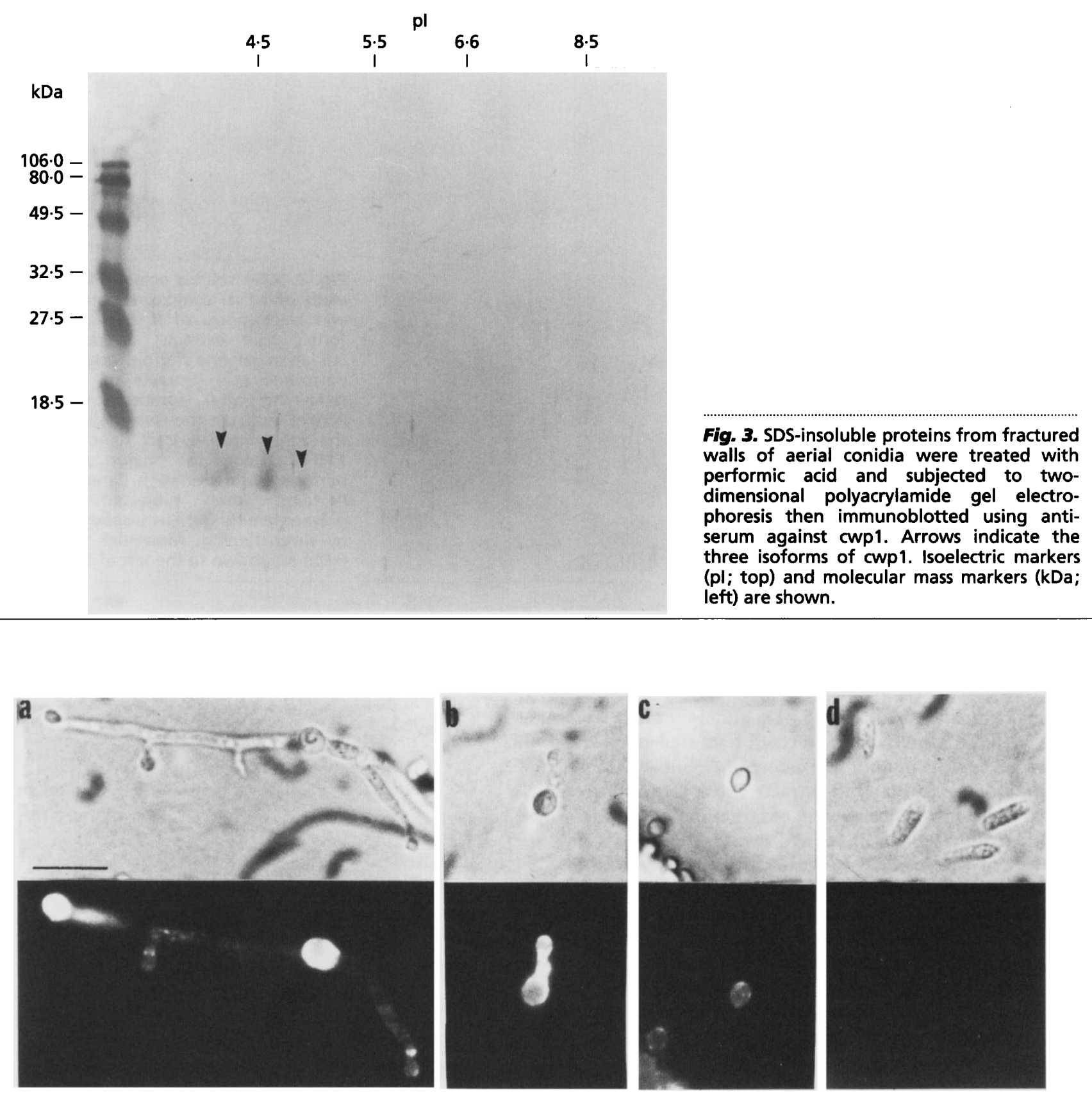

Fig. 4. Bright field (top) and immunofluorescence (bottom) micrographs of (a) submerged conidia developing from hyphae, (b) microcycle conidiation of submerged conidia, (c) aerial conidia and (d) blastospores of $B$. bassiana. Samples were boiled in $5 \% \beta$-mercaptoethanol and subjected to immunofluorescence labelling with antiserum against cwp1. Bar, $10 \mu \mathrm{m}$.

Immunoblotting of the oxidized (performic-acid treated) protein after two-dimensional gel electrophoresis showed that the cwp1 has at least three isoforms ranging from pI 4.0 to $4 \cdot 8$ (Fig. 3).

The cwp1 antibodies showed no immunoreactivity to the SDS-insoluble, formic acid/performic-acid-treated proteins from conidia of the entomopathogenic fungi $M$. anisopliae or $V$. lecanii.

\section{Immunofluorescence of cwp1 in vivo}

Fig. 4(a) shows the formation of submerged conidia from hyphal structures after $3 \mathrm{~d}$ growth in modified TKI broth. Mature conidia fluoresced more strongly than either the immature conidia or the hyphae. Microcycle conidiation was observed in TKI broth (Fig. 4b). The germinated conidia, the stalk and newly formed conidia fluoresced. Aerial conidia boiled with $\beta$-mercaptoethanol then treated 
Table 1. Amino acid analysis of $B$. bassiana cwp1

\begin{tabular}{|lccc|}
\hline Residue & nmol & nmol ratio* & No. of residues \\
\hline Ala & 0.601 & 1.00 & 12 \\
Arg & 0.207 & 0.34 & 4 \\
Asx & 0.649 & 1.08 & 13 \\
Cys & 0.313 & 0.52 & 6 \\
Glx & 0.527 & 0.88 & 10 \\
Gly & 1.339 & 2.23 & 28 \\
His & 0.247 & 0.41 & 5 \\
Ile & 0.292 & 0.49 & 6 \\
Leu & 0.882 & 1.47 & 17 \\
Lys & 0.341 & 0.56 & 8 \\
Met & 0.073 & 0.12 & $1 \dagger$ \\
Phe & 0.057 & 0.09 & $1 \dagger$ \\
Pro & 0.277 & 0.46 & 6 \\
Ser & 0.548 & 0.91 & 11 \\
Thr & 0.531 & 0.88 & 3 \\
Tyr & 0.163 & 0.27 & 9 \\
Val & 0.432 & 0.72 & \\
\hline
\end{tabular}

* Ratio of nmol to those of Ala.

† To obtain a molecular mass value approximated to that calculated by SDS-PAGE we assumed one residue each of Met and Phe per molecule. Assuming the calculated amino acid residue number, the molecular mass is $16079 \mathrm{Da}$.

with cwp1 antibody fluoresced with Cy3 (Fig. 4c). Blastospores showed very weak or no fluorescence (Fig. $4 d)$. Aerial or submerged conidia fluoresced weakly if not previously boiled in $\beta$-mercaptoethanol. Aerial conidia fluoresced more strongly if previously sonicated to remove cell wall surface rodlets (data not shown).

\section{Amino acid analysis}

Sequencing of the $\mathrm{N}$-terminus of cwp1 revealed the sequence: Ser-Gly-His-His-Gly-Gly-Lys-Asp-Leu-HisLys- $X^{\prime}$-Thr-Leu-Gly-Glu-Ala-Gly-Asp-Arg-X-Gly-AlaAsp (where $\mathrm{X}^{\prime}$ is a non-standard amino acid or a modified amino acid but not hydroxyproline and $\mathrm{X}$ is an unresolved amino acid). Sequence analyses were identical for cell wall protein extracts from aerial or submerged conidia. A search for homologous sequences (GCG gene analysis package available to us as a service from the Cornell Biotechnology Program) showed no significant relationships between cwp1 and other fungal proteins.

Amino acid analysis of cwp 1 is presented in Table 1. The protein is rich in glycine (18.5\% of residues) and leucine (11\% of residues). The molecular mass estimated by amino acid analysis is $16079 \mathrm{Da}$, which is in close approximation to the molecular mass estimated by SDSPAGE $(15400 \mathrm{Da})$. cwp1 has a polarity index (Capaldi \& Vanderkooi, 1972) of 42.3 , indicating that in total it is a slightly hydrophobic protein in spite of the $\mathrm{N}$-terminus containing an abundance of hydrophilic amino acids such as histidine, lysine, aspartic acid, glutamic acid, threonine and arginine. However, amino acid analyses should be interpreted cautiously since the reliability differs for different amino acid residues and cysteine residues are particularly difficult to assess.

\section{DIsCussion}

After removal of the rodlet layer from B. bassiana conidia, SDS-insoluble, formic-acid-extractable proteins with molecular masses of $12.8 \mathrm{kDa}$ and $14.0 \mathrm{kDa}$ were found in fractured cell walls of aerial conidia and submerged conidia. Performic-acid treatment of this material resulted in a shift toward a lower mobility in the SDS-PAGE to an apparent single product of $15.4 \mathrm{kDa}$ (cwp1). Oxidation of hydrophobins extracted from rodlets of $B$. bassiana (Bidochka et al., 1995) and from cell walls of other fungi (de Vries et al., 1993) also resulted in a shift toward a lower mobility. Oxidation of cysteine residues to cysteic acids results in relaxation of the protein so that the apparent molecular mass increased. We had initially believed cwp1 to be of the 'hydrophobin' class of fungal wall proteins since it filled several of the criteria in being (1) a lowmolecular-mass protein from fungal walls which was (2) SDS-insoluble, (3) soluble in formic acid, and (4) when oxidized with performic acid the resultant protein was of higher molecular mass. cwp1 contains at least six cysteine residues which could be involved in disulfide bond formation. N-terminal sequence analysis revealed no homologies to known hydrophobins including the $B$. bassiana rodlet protein (Bidochka et al., 1995). However, this does not necessarily exclude cwp1 as a hydrophobin. The $\mathrm{N}$-terminal region of the RodA hydrophobin from Aspergillus nidulans (Stringer et al., 1992) does not show sequence similarities with other hydrophobins (Stringer \& Timberlake, 1993). The question of whether cwp1 is a hydrophobin can only be settled by internal amino acid sequence analysis or from the coding sequence of cwp1 cDNA.

Hydrophobin and cwp1 are apparently important to the insoluble complex of the walls of aerial and submerged conidia but not blastospores of $B$. bassiana. It is not uncommon for more than one SDS-insoluble protein complex to be found in walls of fungi. Three hydrophobin-like proteins are found in Schizopbyllum commune (Wessels et al., 1991) and one, two or three SDS-insoluble, formic-acid-soluble proteins were found in Basidiomycetes and Ascomycetes (de Vries et al., 1993). cwp1 may be specific to $B$. bassiana since $M$. anisopliae and $V$. lecanii cell wall proteins did not immunoreact with the cwp1 antibody.

B. bassiana cwp1 and hydrophobin may represent the major SDS-insoluble proteins of the inner and outer cells walls in conidia, respectively. An electron microscopic study of conidiogenesis and wall formation in Aspergillus niger revealed that the inner and outer cell walls of mature conidia are laid down by the conidium protoplast (Tiedt, 1993). The electron-dense surface coating originates from secreted material which polymerizes when exposed to air. This is consistent with the observation of Wessels (1992) that hydrophobins polymerize on the fungal cell wall when exposed to air. The electron-dense surface coating is 
also consistent with the outer rodlet layer, composed primarily of hydrophobin (Bidochka et al., 1995; BellPeterson et al., 1992; Stringer et al., 1992; Lauter et al., 1992). Removal of the outer rodlet layer revealed that cwp1 is the major SDS-insoluble protein underlying the rodlet layer in B. bassiana.

B. bassiana cwp1 and hydrophobin are both found in aerial or submerged conidia but not in blastospores and may be a class of developmentally regulated proteins that appear to be produced concurrently. We can only speculate as to the reasons why cwp1 is found in submerged conidia and not in blastospores. cwp1 may be regulated through environmental cues through differences in the culture medium as previously outlined for hydrophobin production in B. bassiana (Bidochka et al., 1995).

When fungi are grown under submerged conditions hydrophobins are released into the extracellular medium (Wessels, 1992). This is not clearly so for cwp1. The cwp1 antigen did not immunoreact with a $15.4 \mathrm{kDa}$ protein from culture filtrates or proteins extracted from infected insect haemolymph. The antibody did, however, react with higher molecular mass proteins and this could represent cwp1 complexes, or a nonspecific interaction.

Strategies for propagating $B$. bassiana and other entomopathogenic fungi may influence cell wall properties of the fungus which affect its viability, hydrophobicity and ability to infect insects. Further work examining the regulation, production, deposition and assembly of cwp1 and hydrophobin on the inner and outer cell walls is required.

\section{ACKNOWLEDGEMENTS}

This work was supported by the Natural Sciences and Engineering Research Council of Canada; the Grasshopper Integrated Pest Management Program, APHIS, USDA, Boise, Idaho; the USDA Competitive Research Grants Office (92-37302-7791); and a grant from EcoScience Corp.

\section{REFERENCES}

Bell-Peterson, D., Dunlap, J. C. \& Loros, J. J. (1992). The Neurospora circadian clock-controlled gene, $c c g-2$, is allelic to eas and encodes a fungal hydrophobin required for formation of the conidial rodlet layer. Genes \& Dev 6, 2382-2394.

Bidochka, M. J., Pfeifer, T. A. \& Khachatourians, G. G. (1987). Development of the entomopathogenic fungus Beaveria bassiana in liquid cultures. Mycopatbologia 99, 77-83.

Bidochka, M. J., St Leger, R. J., Joshi, L. \& Roberts, D. W. (1995). The rodlet layer from aerial and submerged conidia of the entomopathogenic fungus Beauveria bassiana contains hydrophobin. Mycol Res (in press).

Boucias, D. G., Pendland, J. C. \& Latge, J. P. (1988). Nonspecific factors involved in attachment of entomopathogenic Deuteromycetes to host insect cuticle. Appl Environ Microbiol 54, 1795-1805.
Capaldi, R. A. \& Vanderkooi, G. (1972). The low polarity of many membrane proteins. Proc Natl Acad Sci US A 69, 930-932.

Cole, G. T., Takashi, S., Kasai, R., Yokoyama, T. \& Nozawa, Y. (1979). Surface ultrastructure and chemical composition of the cell walls of conidial fungi. Exp Mycol 3, 132-156.

Hegedus, D. D., Bidochka, M. J. \& Khachatourians, G. G. (1990). Beauveria bassiana submerged conidia production in a defined medium containing chitin, two hexosamines or glucose. Appl Microbiol Biotechnol 33, 641-647.

Hegedus, D. D., Bidochka, M. J., Miranpuri, G. S. \& Khachatourians, G. G. (1992). A comparison of the virulence, stability and cell-wall surface characteristics of three spore types produced by the entomopathogenic fungus Beauveria bassiana. Appl Microbiol Biotechnol 36, 785-789

Henrikson, R. L. \& Meredith, S. C. (1984). Amino acid analysis by reverse-phase high-performance liquid chromatography: precolumn derivatization with phenylisothiocyanate. Anal Biochem 136, 65-74.

Laemmli, U. K. (1970). Cleavage of structural proteins during the assembly of the head of bacteriophage T4. Nature 227, 680-685.

Lauter, F.-R., Russo, V. E. A. \& Yanofsky, C. (1992). Development and light regulation of eas, the structural gene for the rodlet protein of Neurospora. Genes \& Dev 6, 2373-2381.

Moos, M., Jr, Nguyen, N. Y. \& Liu, T.-Y. (1988). Reproducible high yield sequencing of proteins electrophoretically separated and transferred to an inert support. J Biol Chem 263, 6005-6008.

Reddy, S. R. R. \& Wyatt, G. R. (1967). Incorporation of uridine and leucine in vitro by cecropia silkmoth wing epidermis during diapause and development. J Insect Physiol 13, 981-994.

Stringer, M. A. \& Timberlake, W. E. (1993). Cerato-ulmin, a toxin involved in dutch elm disease, is a fungal hydrophobin. Plant Cell 5, 145-146.

Stringer, M. A., Dean, R. A., Sewall, T. C. \& Timberlake, W. E. (1992). Rodletless, a new Aspergillus developmental mutant induced by directed gene inactivation. Genes \& Dev 5, 1161-1171.

Thomas, K. C., Khachatourians, G. G. \& Ingledew, W. M. (1987). Production and properties of Beauveria bassiana conidia in submerged culture. Can J Microbiol 33, 12-20.

Tiedt, L. R. (1993). An electron microscope study of conidiogenesis and wall formation of conidia of Aspergillus niger. Mycol Res 97, 1459-1462.

de Vries, O. M. H., Fekkes, M. P., Wosten, H. A. B. \& Wessels, J. G. H. (1993). Insoluble hydrophobin complexes in the walls of Schizopbyllum commune and other filamentous fungi. Arch Microbiol 159, 330-335.

Wessels, J. G. H. (1992). Gene expression during fruiting in Scbizopbyllum commune. Mycol Res 96, 609-620.

Wessels, J. G. H., de Vries, O. M. H., Ásgeirsdóttir, S. A. \& Springer, J. (1991). The thn mutation of Schizopbyllum commune, which suppresses formation of aerial hypae, affects expression of the Sc3 hydrophobin gene. J Gen Microbiol 137, 2439-2445.

Received 24 October 1994; revised 13 January 1995; accepted 23 January 1995. 